\title{
The Diffusing Characteristics and Pressure-Volume Relation- ships of the Pulmonary Capillary Bed in Mitral Valve Disease*
}

\author{
R. M. MCCREDIE $\dagger$ \\ (From the Hallstrom Institute of Cardiology, Royal Prince Alfred Hospital, \\ Sydney, Australia)
}

In 1957, Forster, Roughton, and their associates reported a method of estimating pulmonary capillary blood volume $(\mathrm{Vc})$ and diffusing capacity of the alveolar-capillary membrane (DM) by measuring the diffusing capacity of the lung for carbon monoxide (DL) at varying levels of alveolar oxygen tension $(1,2) \cdot{ }^{1}$ Since then there have been a number of reports on the behavior of membrane diffusion and pulmonary capillary blood volume under physiological and pharmacological stresses (3-7) and in certain disease states (8-17).

The purpose of this study was to measure the pulmonary capillary blood volume in normal subjects and in patients with mitral valve disease and to relate the findings to intravascular pressure and flow data obtained by cardiac catheterization.

Most of the studies relating membrane diffusion and pulmonary capillary blood volume to hemodynamic data $(5,10,11)$ have used a breath-holding method of estimating diffusing capacity of carbon monoxide (18). The physiological situation within the pulmonary circulation during the breath-holding maneuver differs from that in the resting steady state. For this reason, the steadystate method described in this report was designed to measure $\mathrm{Vc}$ so that the volume of blood in the pulmonary capillary bed could be compared with the pressure and flow relationships under the same physiological conditions.

* Submitted for publication January 24, 1964; accepted August 7, 1964.

$\dagger$ Research fellow, National Heart Foundation of Australia.

1 The symbols DL, DM, and Vc, used in the original report (2) and in nearly all subsequent reports on this topic, have been retained here.

\section{Methods}

Two groups were studied: 1) The control group consisted of 18 normal subjects, nine of whom were laboratory personnel with no evidence of cardiorespiratory disease; nine were patients with systolic murmurs in whom no other abnormality was detected by physical examination, ECG, and chest $\mathrm{X}$ ray, or at cardiac catheterization. 2) The abnormal group comprised 18 patients with mitral valve disease, 15 of whom had pure mitral stenosis and three who had dominant mitral incompetence.

Cardiac catheterization was performed by standard procedures (19) in the 18 patients with mitral valve disease and in the nine normal subjects who had systolic murmurs. In the normal subjects, catheterization of the right heart only was performed, and pulmonary arterial wedge pressure was obtained as an estimate of left atrial pressure. Left heart catheterization was also performed in all the patients with mitral valve disease, by the transeptal approach (20), and left atrial pressure was recorded directly. Cardiac output was measured by indicator dilution techniques (21) ; injections of cardiogreen dye were made into the pulmonary artery or left atrium, and dilution curves were recorded from a peripheral artery with a Gilford densitometer. Arterial oxygen saturation was estimated by the spectrophotometric method of Roos and Rich, which is accurate to within $1 \%$ in this laboratory (22)..$^{2}$ Before catheterization, all subjects were premedicated with omnoponscopolamine (Papaveretum, B.P.C., with hyoscine hydrobromide).

DL was determined by a modification of the steadystate technique described by Bates, Boucot, and Dormer (23). The apparatus consisted of a mouthpiece with unidirectional valves to which was attached a Rahn-Otis type of end-tidal sampler (24),,$^{3}$ which extracts 30 to 40 $\mathrm{ml}$ of gas from the end of each expiration just beyond the expiratory valve. The inspiratory side of the mouthpiece was attached through 1-inch i.d. plain rubber tubing to a Tissot $120-\mathrm{L}$ spirometer. A pen was attached to the sliding scale of the spirometer and ventilation (inspired) recorded directly on a motor-driven kymograph.

2 Beckman model D.U. spectrophotometer, Beckman Instruments, South Pasadena, Calif.

3 Godart Mijnhardt Ltd., Utrecht, Holland. 
Subjects were studied at rest in the recumbent position. A Riley needle was placed in a brachial artery, and after a period of at least 15 minutes, the subject was connected to the mouthpiece and breathed $100 \%$ oxygen for 4 minutes. At the end of 4 minutes he was switched into the Tissot spirometer, containing a mixture of $0.3 \%$ carbon monoxide in oxygen, and he continued to breathe this mixture for a further 4 minutes. Rubber bags placed to collect mixed expired and end-tidal gas were flushed during the first 2 minutes of $\mathrm{CO}$ breathing; during the last 2 minutes, mixed expired and end-tidal gas was collected, and an 8-ml sample of blood was withdrawn into a heparinized syringe at a rate of $4 \mathrm{ml}$ per minute.

The subject was then disconnected from the respiratory circuit for at least 10 minutes. The mixture in the spirometer was changed to $0.1 \%$ carbon monoxide in air and the same procedure repeated except that during the preliminary breathing period, before being switched into the Tissot spirometer, he breathed room air instead of oxygen. The record of ventilation was monitored during this second period of breathing the $\mathrm{CO}$ mixture, and the subject was instructed throughout to adjust his rate and depth of breathing to reproduce as closely as possible the tidal volume and minute ventilation of the first determination. No subject was included in this study who was unable to reproduce the tidal volume and minute ventilation to within $20 \%$ during the two estimations.

Except that no premedication was given, diffusion studies were done under the same conditions as cardiac catheterization studies. The two studies were performed during the same admission to hospital and no more than 4 days apart.

Gas and blood samples were analyzed for carbon monoxide, oxygen, and nitrogen with a Beckman GC2 gas chromatograph. Helium was used as the carrier gas, and $\mathrm{O}_{2}, \mathrm{~N}_{2}$, and $\mathrm{CO}$ were separated by passing through a Linde $5 \mathrm{~A}$ molecular sieve column at $100^{\circ} \mathrm{C}$. The output from the thermal conductivity detector was amplified and recorded on a potentiometric recorder. 4

For analysis of carbon monoxide in gas samples, a 5-ml sample of dry gas was introduced into the carrier gas stream. Over the range of $\mathrm{CO}$ concentration required, 0 to $0.4 \%$, peak output is linearly related to concentration. With this size sample, peak outputs for $\mathrm{O}_{2}$ and $\mathrm{N}_{2}$ are not linearly related to concentration, but the areas under the recorded peaks are. Although a mechanical disc integrator can be used to measure and record these areas during the analysis, it was found to be more satisfactory to introduce another much smaller sample of each gas for the analysis of $\mathrm{O}_{2}$ and $\mathrm{N}_{2}$. For this purpose, volumes of $0.1 \mathrm{ml}$ and $0.05 \mathrm{ml}$ were used, and with these volumes peak height was linearly related to concentration over a range of 0 to $100 \%$ for both $\mathrm{O}_{2}$ and $\mathrm{N}_{2}$. The record was calibrated by intro-

\footnotetext{
${ }^{4}$ Honeywell Controls Ltd., Newhouse, Lanarkshire,
} Scotland. ducing the same volumes of standard dry gas mixtures with known concentrations of $\mathrm{O}_{2}, \mathrm{~N}_{2}$, and CO.

Blood gases were extracted under vacuum in a Van Slyke extraction chamber, with a standard potassium ferricyanide reagent to liberate $\mathrm{O}_{2}$ and $\mathrm{CO}$. The extracted gases were injected through a side-arm into the carrier gas line and recorded in the same way. Calibration was obtained by injecting an accurately measured volume of pure $\mathrm{O}_{2}, \mathrm{~N}_{2}$, or $\mathrm{CO}$ into the carrier gas stream at the same point, and results of blood gas analyses were expressed at STPD (standard temperature, pressure, dry). Carbon dioxide and water were absorbed with a sodium hydrate asbestos absorber (Ascarite $^{5}$ ) and anhydrous magnesium perchlorate (Dehydrite ${ }^{5}$ ) after being injected into the carrier gas stream but before entering the molecular sieve column. The standard deviation of repeated measurements of all these gases in gas samples was under $\pm 1 \%$ over the range of concentrations required in these studies, and that of blood samples was less than $\pm 2 \%$ of the mean values.

DL was computed for each of the two 2-minute periods during which the measurements were made, by following the methods discussed by Forster and associates (1) and Bates and associates (23).

Mean pulmonary capillary plasma $\mathrm{CO}$ tension was calculated by rearranging the Haldane equation assuming that carboxyhemoglobin $(\mathrm{COHb})$ saturation in arterial blood is representative of that in pulmonary capillary blood, according to the method described by Forster and associates (1). The $\mathrm{COHb}$ saturation was $\mathrm{CO}$ content divided by $\mathrm{CO}$ capacity expressed as a percentage; $\mathrm{CO}$ capacity was derived from $\mathrm{O}_{2}$ capacity and $\mathrm{CO}$ content of the same blood sample.

Values for $\mathrm{DM}_{\mathrm{M}}$ and $\mathrm{Vc}$ were obtained by graphic solution of the equation $1 / \mathrm{DL}_{L}=1 / \mathrm{D}_{\mathrm{M}}+1 / \theta \mathrm{Vc}$ for the two determinations of DL at different alveolar oxygen tensions. The values of $\theta$, the reaction rate between $\mathrm{CO}$ and $\mathrm{Hb}$, used were obtained from the data of Roughton, Forster, and their co-workers $(2,25,26)$, assuming a ratio of membrane to interior of the red cell permeability of 2.5. Values of $\theta$ were corrected for the $\mathrm{CO}$ capacity of each individual.

In the first measurement of $D_{L}$, samples of end-tidal air were collected during the minutes 7 and 8 of breathing oxygen-4 minutes of $100 \% \mathrm{O}_{2}$ and 4 minutes of $0.3 \% \mathrm{CO}$ in $\mathrm{O}_{2}$. The concentration of nitrogen in the end-tidal air is therefore comparable to the concentration of nitrogen sampled at the mouth after 7 minutes in the standard nitrogen washout test and provides an index of the distribution of ventilation (27). In none of the normal subjects and in only one of the patients with mitral valve disease was the end-tidal nitrogen concentration above $1.5 \%$ at this time.

Values for $\mathrm{DL}_{L}, \mathrm{DM}_{\mathrm{M}}$, and $\mathrm{Vc}$ were related to BSA; DL and DM were expressed in milliliters $C O$ per minute per millimeter $\mathrm{Hg}$ per square meter and $\mathrm{Vc}$ in milliliters per square meter. The ratio of membrane to in-

\footnotetext{
5 Arthur H. Thomas Co., Philadelphia, Pa.
} 
$D_{L}$

$\mathrm{ml} \mathrm{CO} / \mathrm{min} \times \mathrm{mmHg} \times \mathrm{M}^{2}$

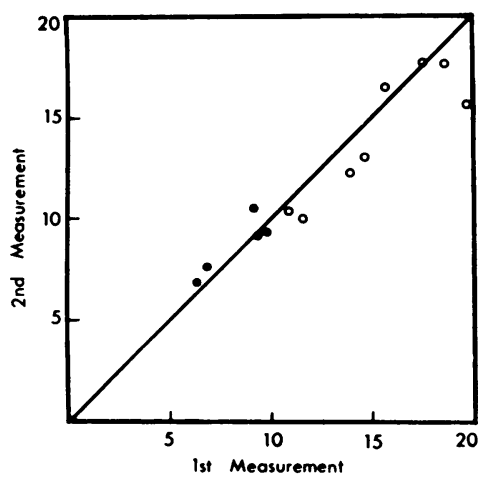

A
$D_{M}$

$m \mathrm{llO} / \mathrm{min} \times \mathrm{mmHg} \times \mathrm{M}^{2}$

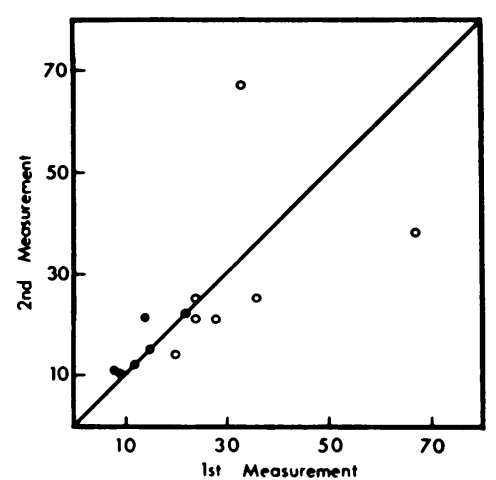

B
$V_{C}$

$m / m^{2}$

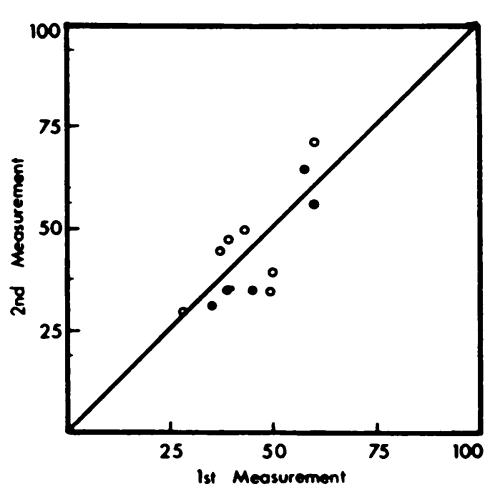

C $\quad V_{C} \mathrm{ml} / \mathrm{m}^{2}$

Fig. 1. Comparison between duplicate determinations of the diffusing capacity of the lung (DL), the DIFFUSING CAPACITY OF THE ALVEOLAR-CAPILLARY MEMBRANE (DM), AND THE PULMONARY CAPILLARY BLOOD VOLUME (VC) DONE IN 13 SLBJECTS, EIGHT NORMAL (CIRCLES) AND FIVE WITH HEART DiSEASE (DOTS), ON DifFERENT DAYS.

tracapillary resistance to diffusion $(\mathrm{RM} / \mathrm{Rc})$ was calculated by the methods discussed by Roughton and Forster (2) and McNeill, Rankin, and Forster (8). Pulmonary vascular resistance (PVR) was expressed in resistance units and also related to body surface area $\left(\mathrm{RU} \cdot \mathrm{m}^{2}\right)$; it was obtained by dividing the difference between mean pulmonary arterial pressure $(\overline{P A})$ and mean left atrial pressure $(\mathrm{P} \overline{\mathrm{LA}})$ in millimeters $\mathrm{Hg}$ by the cardiac index in liters per minutes per square meter.

The reproducibility of measurements of DL, DM, and Vc with this technique has been estimated by doing duplicate determinations on eight normal subjects and five other patients with heart disease on different days.

\section{Results}

As judged from duplicate determinations (Figure 1), the standard deviations (28) of each measurement were for $\mathrm{DL} \pm 1.12 \mathrm{ml} \mathrm{CO}$ per minute per $\mathrm{mm} \mathrm{Hg}$ per $\mathrm{m}^{2}$; for $\mathrm{Dm}_{\mathrm{M}} \pm 9.32 \mathrm{ml} \mathrm{CO}$ per minute per $\mathrm{mm} \mathrm{Hg}$ per $\mathrm{m}^{2}$; and for $\mathrm{Vc} \pm 5.66 \mathrm{ml}$ per $\mathrm{m}^{2}$. These represented $9.1 \%, 39.0 \%$, and $12.4 \%$ of the mean values, respectively, and compound day to day physiological variations with errors in the method. The relatively poor reproducibility of $\mathrm{DM}$ is largely influenced by the two extreme sets of duplicates seen in Figure 1B. If these are omitted, the standard deviation for $\mathrm{DM}_{\mathrm{M}}$ is then $3.4 \mathrm{ml} \mathrm{CO}$ per minute per $\mathrm{mm} \mathrm{Hg}$ per $\mathrm{m}^{2}$ or $17.7 \%$ of the mean. This reproducibility of DL, DM, and Vc is similar to that reported by
Bates, Varvis, Donevan, and Christie with exercise studies (9).

Values found for DL, DM, and Vc in 18 normal subjects are listed in Table I. The mean values and standard deviations (mean $\pm \mathrm{SD}$ ) were for DL $15.0 \pm 2.5 \mathrm{ml} \mathrm{CO}$ per minute per $\mathrm{mm} \mathrm{Hg}$ per $\mathrm{m}^{2}$, for DM $30 \pm 10.4 \mathrm{ml} \mathrm{CO}$ per minute per $\mathrm{mm}$ $\mathrm{Hg}$ per $\mathrm{m}^{2}$, and for $\mathrm{Vc} 52 \pm 14.9 \mathrm{ml}$ per $\mathrm{m}^{2}$. The mean $\pm \mathrm{SD}$ for the ratio of membrane to intracapillary resistances $(\mathrm{RM} / \mathrm{Rc})$ in normal subjects was $1.30 \pm 0.63$. Also listed in Table I are the hemodynamic data obtained at cardiac catheterization on the nine normal subjects with systolic murmurs.

Results in 18 patients with mitral valve disease are listed in Table II. The means $\pm \mathrm{SD}$ in this group were for DL $8.0 \pm 2.5 \mathrm{ml} \mathrm{CO}$ per minute per $\mathrm{mm} \mathrm{Hg}$ per $\mathrm{m}^{2}$, for Dm $12 \pm 4.4 \mathrm{ml} \mathrm{CO}$ per minute per $\mathrm{mm} \mathrm{Hg}$ per $\mathrm{m}^{2}$, and for $\mathrm{Vc} 43 \pm 18.1$ $\mathrm{ml}$ per $\mathrm{m}^{2}$. The mean $\pm \mathrm{SD}$ of the $\mathrm{Rm} / \mathrm{Rc}$ ratio was $3.04 \pm 1.95$. Hemodynamic data on these patients are also listed in Table II.

Figure 2 shows a comparison between normal subjects and patients with mitral valve disease for DL, DM, and Vc. In patients with mitral valve disease, the reduction in mean total diffusing capacity of the lungs as compared with normal is highly significant $(p<0.001)$, and the reduction in mean membrane diffusing capacity is also highly significant $(p<0.001)$. There is, how- 
TABLE I

Physical characteristics and determinations of $D_{L}, D_{M}, V c$, and hemodynamic data in normal subjects*

\begin{tabular}{|c|c|c|c|c|c|c|c|c|c|c|}
\hline \multicolumn{3}{|c|}{ Normal subjects } & \multirow[b]{2}{*}{ DL } & \multirow[b]{2}{*}{ DM } & \multirow[b]{2}{*}{$\mathrm{Vc}$} & \multirow[b]{2}{*}{$\mathrm{RM} / \mathrm{Rc}$} & \multirow[b]{2}{*}{$\mathrm{P} \overline{\mathrm{PA}}$} & \multirow[b]{2}{*}{$\mathrm{P} \overline{\mathrm{LA}}$} & \multirow[b]{2}{*}{ C.I. } & \multirow[b]{2}{*}{$\mathrm{SaO}_{2}$} \\
\hline Age & Sex & BSA & & & & & & & & \\
\hline & & $m^{2}$ & $\begin{array}{c}m l C O / \min / \\
m m ~ H g / m^{2}\end{array}$ & $\begin{array}{l}m l \mathrm{CO} / \mathrm{min} / \\
\mathrm{mm} \mathrm{Hg} / \mathrm{m}^{2}\end{array}$ & $m l / m^{2}$ & & $m m H g$ & $m m H g$ & $L / \mathrm{min} / \mathrm{m}^{2}$ & $\%$ \\
\hline 20 & $\mathrm{~F}$ & 1.60 & 13.1 & 22 & 44 & 1.47 & & & & \\
\hline 29 & M & 1.88 & 18.2 & 52 & 41 & 0.54 & & & & \\
\hline 30 & $\mathrm{M}$ & 1.90 & 17.4 & 50 & 34 & 0.53 & & & & \\
\hline 30 & M & 1.87 & 13.9 & 24 & 46 & 1.38 & & & & \\
\hline 29 & $\mathrm{M}$ & 1.95 & 17.8 & 30 & 48 & 1.46 & & & & \\
\hline 32 & $\mathrm{M}$ & 1.99 & 10.8 & 17 & 43 & 1.74 & & & & \\
\hline 30 & $\mathbf{M}$ & 1.87 & 16.1 & 24 & 67 & 2.04 & & & & \\
\hline 46 & $\mathbf{M}$ & 1.83 & 10.7 & 21 & 29 & 1.04 & & & & \\
\hline 28 & $\mathbf{M}$ & 1.90 & 15.4 & 42 & 33 & 0.58 & & & & \\
\hline 10 & $\mathbf{M}$ & 1.30 & 12.9 & 23 & 55 & 1.61 & 18 & 11 & 3.8 & 100 \\
\hline 19 & $\mathbf{M}$ & 1.62 & 12.3 & 16 & 67 & 3.13 & 22 & 11 & 3.3 & 95.6 \\
\hline 12 & $\mathrm{~F}$ & 1.48 & 18.5 & 37 & 68 & 0.95 & 9 & 3 & 3.3 & 95.6 \\
\hline 17 & $\mathrm{M}$ & 1.68 & 14.5 & 24 & 53 & 0.94 & 11 & & 3.4 & 93.4 \\
\hline 8 & M & 0.91 & 14.8 & 33 & 52 & 0.84 & 16 & 9 & 3.6 & 98.3 \\
\hline 21 & $\mathbf{M}$ & 1.95 & 17.6 & 37 & 53 & 1.02 & 8 & 6 & 3.8 & 98.5 \\
\hline 11 & $\mathbf{M}$ & 1.26 & 17.1 & 28 & 90 & 1.20 & 12 & 6 & 3.1 & 97.0 \\
\hline 11 & $\mathrm{M}$ & 1.10 & 16.6 & 30 & 59 & 1.46 & 14 & 7 & 4.4 & 97.0 \\
\hline \multirow[t]{3}{*}{15} & $F$ & 1.80 & 13.1 & 24 & 49 & 1.52 & 9 & 5 & 2.7 & 98.6 \\
\hline & & Mean & 15.0 & 30 & 52 & 1.30 & 13 & 7 & 3.5 & \\
\hline & & $\mathrm{SD}$ & 2.52 & 10.4 & 14.9 & 0.63 & 4.7 & 2.9 & 0.5 & \\
\hline
\end{tabular}

* DL and DM are the diffusing capacities of the lung and of the alveolar-capillary membrane; Vc is the pulmonary capillary blood volume. $\mathrm{RM} / \mathrm{Rc}$ is the ratio of membrane resistance to intracapillary resistance to diffusion. P $\overline{\mathrm{PA}}$ is the mean pulmonary arterial pressure; P $\overline{\mathbf{L A}}$ is the mean left atrial pressure; C.I. is the cardiac index. Saoz is the arterial oxygen saturation.

TABLE II

Physical characteristics and determinations of $D_{L}, D_{M}, V c$, and hemodynamic data in patients with mitral valve disease*

\begin{tabular}{|c|c|c|c|c|c|c|c|c|c|c|}
\hline \multicolumn{3}{|c|}{ Mitral valve disease } & \multirow[b]{2}{*}{ DL } & \multirow[b]{2}{*}{ DM } & \multirow[b]{2}{*}{ Vc } & \multirow[b]{2}{*}{$\mathbf{R M} / \mathbf{R c}$} & \multirow[b]{2}{*}{$\overline{P P A}$} & \multirow[b]{2}{*}{$\mathrm{P} \overline{\mathrm{LA}}$} & \multirow[b]{2}{*}{ C.I. } & \multirow[b]{2}{*}{$\mathrm{SaO}_{2}$} \\
\hline Age & Sex & BSA & & & & & & & & \\
\hline & & $m^{2}$ & $\begin{array}{l}m l \mathrm{CO} / \mathrm{min} / \\
\mathrm{mm} \mathrm{Hg} / \mathrm{m}^{2}\end{array}$ & $\underset{m m \mathrm{mg} / \mathrm{m}^{2}}{\operatorname{mlCO} / \min /}$ & $m l / m^{2}$ & & $m m \mathrm{Hg}$ & $m m \mathrm{Hg}$ & $L / \min / m^{2}$ & $\%$ \\
\hline 42 & $\mathrm{~F}$ & 1.32 & 6.6 & 8 & 77 & 6.68 & 27 & 14 & 2.1 & 95.0 \\
\hline 30 & $\mathrm{~F}$ & 1.41 & 9.9 & 17 & 38 & 1.44 & 40 & 24 & 1.8 & 96.5 \\
\hline 44 & $\mathrm{M}$ & 1.84 & 6.9 & 9 & 37 & 3.95 & 39 & 18 & 2.8 & 94.0 \\
\hline 36 & $\mathrm{~F}$ & 1.76 & 7.3 & 9 & 58 & 4.76 & 26 & 21 & 2.3 & 96.0 \\
\hline 59 & $\mathrm{M}$ & 1.89 & 5.5 & 10 & 17 & 1.21 & 59 & 24 & 2.5 & 97.0 \\
\hline 28 & $\mathrm{~F}$ & 1.48 & 15.1 & 23 & 74 & 2.12 & 22 & 18 & 3.1 & 96.0 \\
\hline 36 & $\mathrm{M}$ & 1.87 & 9.6 & 15 & 34 & 1.73 & 35 & 22 & 2.1 & 100.0 \\
\hline 53 & $\mathrm{~F}$ & 1.54 & 6.9 & 13 & 24 & 1.22 & 75 & 37 & 2.5 & 90.7 \\
\hline 48 & $\mathrm{M}$ & 1.89 & 10.4 & 18 & 40 & 1.37 & 35 & 20 & 3.0 & 95.0 \\
\hline 38 & $\mathrm{~F}$ & 1.55 & 7.2 & 10 & 46 & 2.63 & 35 & 24 & 1.6 & 98.0 \\
\hline 35 & $F$ & 1.56 & 9.8 & 16 & 40 & 1.74 & 32 & 26 & 3.1 & 98.0 \\
\hline 35 & $\mathrm{~F}$ & 1.66 & 7.8 & 11 & 43 & 2.65 & 20 & 14 & 3.0 & 97.0 \\
\hline 44 & M & 1.68 & 5.8 & 7 & 48 & 5.13 & 40 & 24 & 1.7 & 98.9 \\
\hline 43 & $\mathrm{~F}$ & 1.44 & 8.5 & 14 & 35 & 6.29 & 28 & 22 & 2.9 & 95.0 \\
\hline 47 & $\mathrm{M}$ & 1.73 & 4.6 & 7 & 29 & 2.20 & 28 & 21 & 1.3 & 91.5 \\
\hline 48 & $\mathrm{~F}$ & 1.50 & 8.5 & 10 & 77 & 6.40 & 22 & 18 & 2.8 & 96.5 \\
\hline 38 & $F$ & 1.63 & 4.9 & 8 & 23 & 1.94 & 31 & 13 & 2.4 & 94.0 \\
\hline \multirow[t]{3}{*}{20} & $\mathrm{~F}$ & 1.40 & 8.4 & 16 & 30 & 1.28 & 58 & 30 & 2.0 & 92.4 \\
\hline & & Mean & 8.0 & 12 & 43 & 3.04 & 36 & 22 & 2.4 & \\
\hline & & $\mathrm{SD}$ & 2.5 & 4.5 & 18.1 & 1.95 & 14.5 & 5.9 & 0.56 & \\
\hline
\end{tabular}

* Symbols are the same as those used in Table I. 

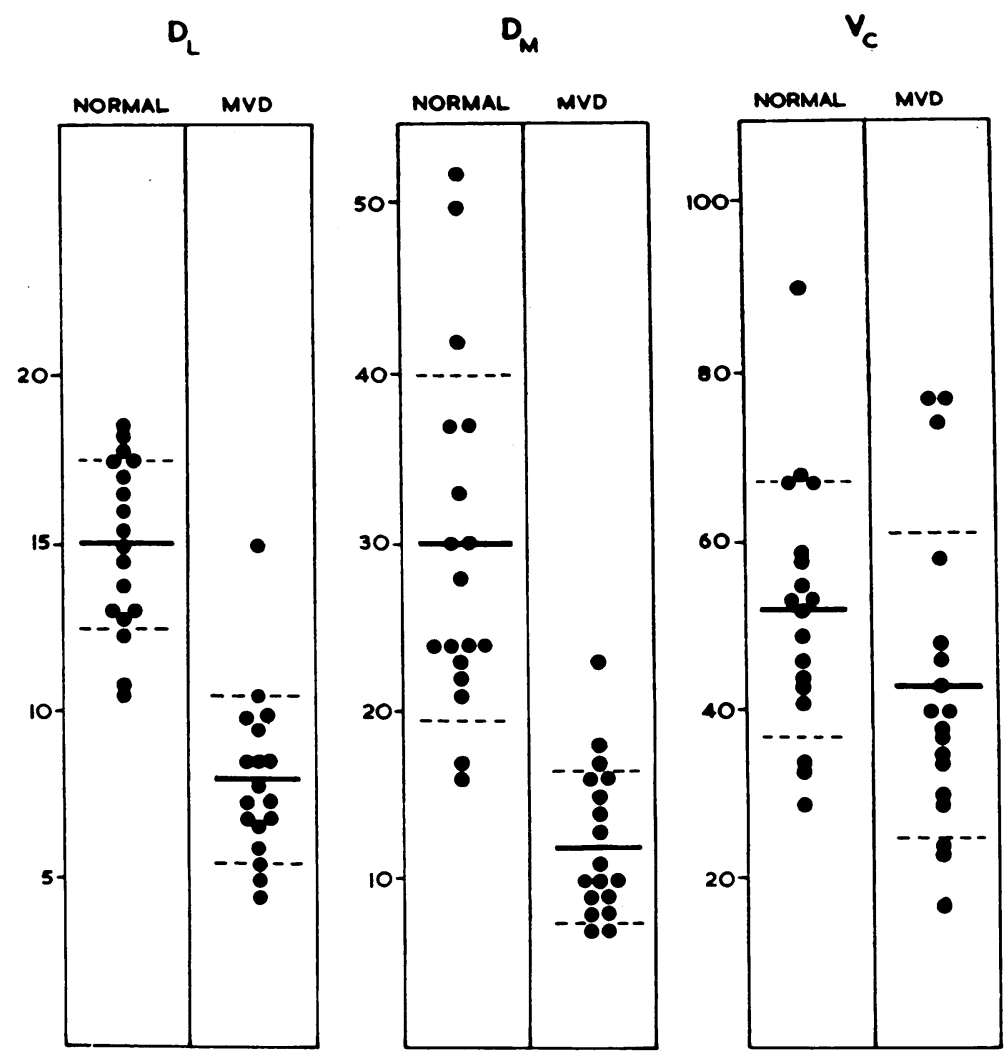

Fig. 2. Comparison of values found for DL and DM, in milliliters CO PER MINUTE PER MILlimeter Hg PER SQUARE METER AND VC IN MILliLITERS PER SQUARE METER BETWEEN NORMAL SUBJECTS AND PATIENTS WITH Mitral valve disease (MVD). There is a highly significant difference in both DL and $D_{M}$ between the two groups $(p<0.001$ in both cases), but there is no significant difference in $\mathrm{Vc}(0.10>\mathrm{p}>0.05)$. Solid and broken lines represent the mean $\pm \mathrm{SD}$ within each group.

ever, no significant difference in the mean values of pulmonary capillary blood volume in the two groups $(0.10>p>0.05)$. There is also a significant difference in $\mathrm{Rm} / \mathrm{Rc}$ ratios between the two groups $(\mathrm{p}<0.01)$.

The results on 27 subjects (nine normal and 18 patients with mitral valve disease), in whom hemodynamic data were obtained, were analyzed for correlations between pulmonary capillary blood volume and the following hemodynamic variables: cardiac index, stroke volume, mean pulmonary arterial pressure, mean left atrial pressure, and pulmonary vascular resistance.

There was a probably significant correlation between $V c$ and cardiac index $(r=+0.382, p<$ 0.05 ) but no correlation between $\mathrm{Vc}$ and stroke volume $(r=+0.257,0.20>p>0.10)$ (Figure $3)$. There was a highly significant negative cor-
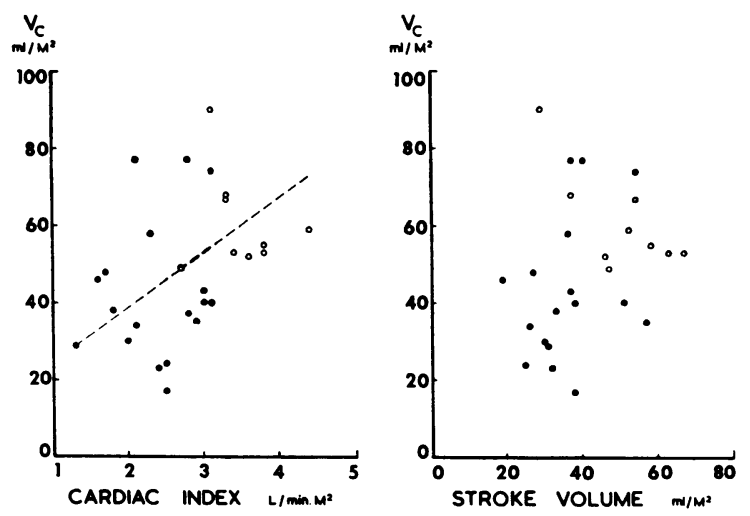

Fig. 3. Relationship between VC and (A) cardiac INDEX AND (B) STROKE VOLUME IN NINE NORMAL SUBJeCTS (CIRCles) and 18 Patients With Mitral valve DISEASE (DOTS). There is a probably significant correlation between $\mathrm{Vc}$ and cardiac index $(\mathrm{r}=+0.382, \mathrm{p}<$ 0.05 ) but no correlation between $\mathrm{Vc}$ and stroke volume $(\mathrm{r}=+0.257,0.20>\mathrm{p}>0.10)$. 


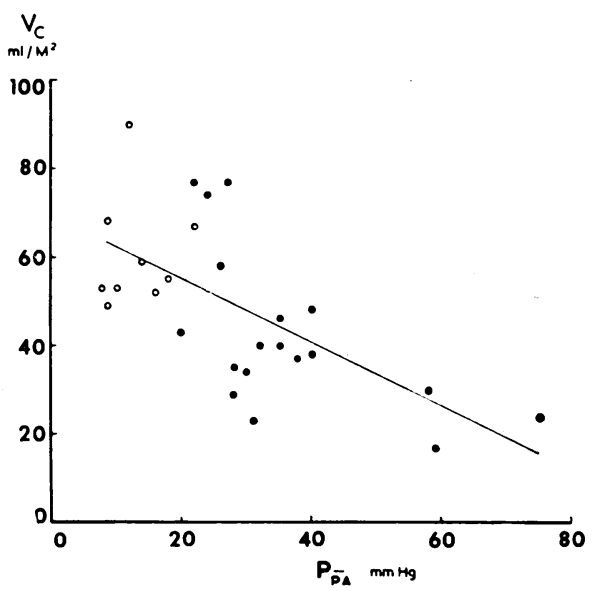

Fig. 4. Relationship between Vc and mean pUl-

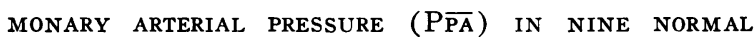
SUBJECTS (CIRCLES) AND 18 PATIENTS WITH MITRAL VALVE DISEASE (DOTS). There is a highly significant negative correlation $(\mathrm{r}=-0.658, \mathrm{p}<0.001)$.

relation between $\mathrm{Vc}$ and mean pulmonary arterial pressure $(\mathrm{r}=-0.658, \mathrm{p}<0.001)$ (Figure 4$)$. There was also a significant negative correlation between $\mathrm{Vc}$ and mean left atrial pressure $(\mathrm{r}=-$ 0.586, $\mathrm{p}<0.01$ ) (Figure 5).

The relationship between $\mathrm{Vc}$ and pulmonary vascular resistance is shown in Figure 6. There is a highly significant negative correlation between $\mathrm{Vc}$ and pulmonary vascular resistance $(\mathrm{r}=-$ $0.647, \mathrm{p}<0.001$ ).

If the normal subjects are omitted from this

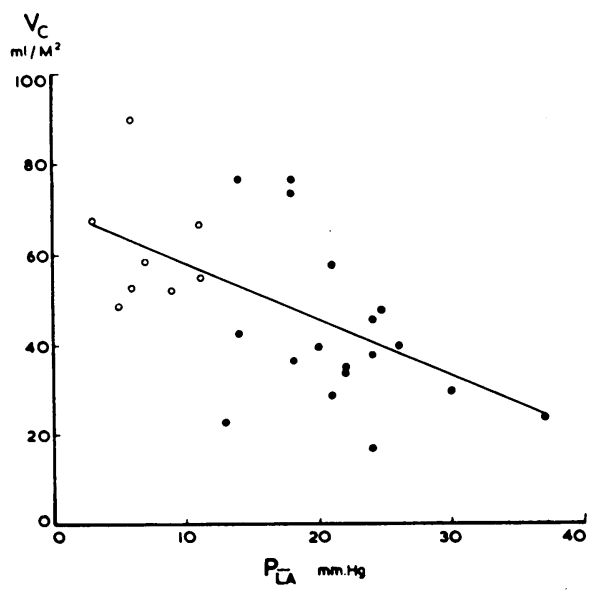

Fig. 5. Relationship Between (Vc) and MEAN LEFT ATRIAL ṔRESSURE (P $\overline{\mathrm{LA}}$ ) IN NINE NORMAL SUBJECTS (CIRCles) AND 18 patients with Mitral valve disEASE (DOTS). There is a significant negative correlation $(\mathrm{r}=-0.586, \mathrm{p}<0.01)$. analysis, then in the 18 patients with mitral valve disease, there are still significant negative correlations between $\mathrm{Vc}$ and mean pulmonary arterial pressure $(\mathrm{r}=-0.606, \mathrm{p}<0.01)$, and pulmonary vascular resistance $(r=-0.612, p<0.01)$, but no correlations between $\mathrm{Vc}$ and cardiac index, stroke volume, or mean left atrial pressure.

\section{Discussion}

The values of DL, DM, and Vc in normal subjects are in good agreement with those found by other workers using either steady-state or breathholding techniques $(2,3,8-11)$.

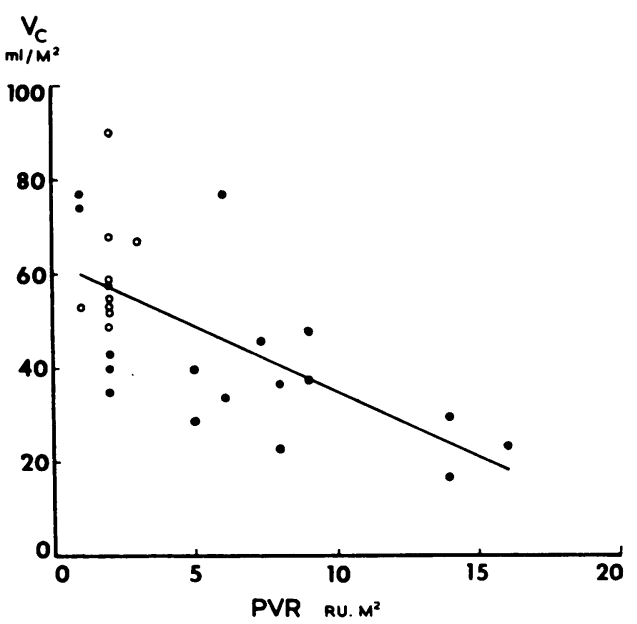

Fig. 6. Relationship BetweEN VC AND PUlmonary VASCULAR RESISTANCE (PVR) IN NINE NORMAL SUBJECTS (CIRCLES) AND 18 PATIENTS With Mitral VALVE DISEASE (DOTS). There is a highly significant negative correlation $(\mathrm{r}=-0.647, \mathrm{p}<0.001) . \quad \mathrm{RU}=$ resistance units.

Several factors that may influence the present estimates of DL, DM, and Vc need to be considered. Uncertainty about the hematocrit of pulmonary capillary blood as compared with arterial blood may affect the absolute value of $\mathrm{Vc}$ (2), but this is unlikely to influence the relationships found here.

The calculated value of De by any steady-state method is very sensitive to errors in the measurement of mean alveolar carbon monoxide tension. These errors are increased in the presence of uneven distribution of ventilation $(29,30)$. Detectable maldistribution of ventilation, as judged by $\mathrm{N}_{2}$ washout, was absent in this series, except 
in one patient, and it seems unlikely that lesser degrees of uneven ventilation contributed a systematic error to DL.

If part of the perfused capillary bed were not ventilated, the measured $\mathrm{Vc}$ would be an underestimate of the true anatomical capillary blood volume. In this situation, there would be a significant venous admixture with arterial desaturation. There was, however, no correlation between $\mathrm{Vc}$ and arterial oxygen saturation, which was above $95 \%$ in all but five patients with mitral valve disease and one normal subject (Tables I and II), so this is unlikely to have contributed a systematic error.

Nonuniform distribution of Vc with respect to alveolar ventilation may result in errors in the estimates of DL, DM, and Vc, and there is evidence that capillary blood flow and volume may be nonuniformly distributed in mitral valve disease with severe pulmonary hypertension (3133). Studies with $\mathrm{O}^{15}$ indicate that in the erect normal subject blood flow through the lower lung zones is greater than through the upper zone, and the distribution of blood flow becomes more uniform in the supine position (34). In patients with mitral stenosis, this difference in the distribution of blood flow between upper and lower zones may be abolished in the erect posture and, in the presence of severe pulmonary vascular disease, may even be reversed (32). Clearance of radioactively labeled $\mathrm{CO}$ and $\mathrm{O}_{2}$ has been used as an index of blood flow but must depend to some extent on capillary blood volume, since the uptake of $\mathrm{CO}$ is wholly diffusion limited and that of $\mathrm{O}_{2}$ partly so. These clearance studies indicate that perfusion of the upper lobes in mitral stenosis may be as much as three times that of the lower lobes in the presence of severe pulmonary vascular disease. According to data derived from a theoretical two-compartment lung model (35), nonuniform distribution of $\mathrm{Vc}$ will result in an underestimate of Vc. It is therefore possible that a systematically increasing underestimate of $\mathrm{Vc}$ with increasingly severe pulmonary hypertension is responsible for the negative correlations found here between $\mathrm{Vc}$ and intravascular pressures and resistance. However, this would require a ratio of distribution of $\mathrm{Vc}$ between upper and lower zones considerably higher than those suggested by the radioactive clearance studies (32); it seems unlikely that this source of error is of sufficient magnitude to explain the relationships found.

The assumption that neither DM nor Vc changes under the influence of high oxygen tension has been discussed in detail by Forster and associates (1) and by Lewis, Lin, Noe, and Komisaruk (3). If $100 \%$ oxygen produces any change either in the over-all pulmonary capillary blood volume or in the distribution of $\mathrm{Vc}$ with respect to alveolar ventilation in patients with mitral valve disease, errors in the estimation of $\mathrm{Vc}$ will result. If the capillary bed enlarges, or becomes more uniformly distributed, under the influence of $100 \%$ oxygen, then an overestimate of $\mathrm{Vc}$ will result; if the capillary bed constricts or becomes more unevenly distributed, Vc will be underestimated. The extent or direction of this possible source of error cannot be predicted on the present information.

The finding that De is commonly, although not invariably, reduced in mitral valve disease is well known $(9,10,16,17,36-39)$. The significant reduction in mean $D L$ in this group of patients with mitral valve disease is due mainly to a reduction in membrane diffusion; in the majority of patients, Vc was within normal limits, which agrees with the recent findings of Daly, Giammona, Ross, and Feigenbaum (17). The mean age of the normal group was 29 years and of the group with mitral valve disease, 41 years; although there is some disagreement about the influence of age on pulmonary diffusing capacity, some workers have reported a mean reduction in steady-state DL of about $20 \%$ over this age range $(9,40)$. Thus this age difference may have contributed in part to the reduction in DL, but would not explain the $50 \%$ reduction in DL and DM found here. A normal Vc, reduced DM, and increased $\mathrm{Rm} / \mathrm{Rc}$ ratio in patients with mitral valve disease can be explained on either of two anatomical concepts. The membrane may be thickened without change in the dimensions of the capillary lumina; alternatively, there could be destruction of some capillaries with dilatation of the remainder so that the total volume of blood in the capillary bed remains normal but DMr is reduced from disproportionate reduction in surface area. A combination of these two effects is probably the correct explanation (41).

A close relationship between Vc and pulmonary 
blood flow has been demonstrated in normal subjects (5) and in patients with left to right shunts (42). In the group analyzed here (Figure 3) there was a poor but probably significant correlation between $\mathrm{Vc}$ and cardiac output. There was no correlation between $\mathrm{Vc}$ and stroke volume. Studies of total pulmonary blood volume in mitral valve disease (43) have demonstrated that pulmonary blood volume is positively related to cardiac output and more closely to stroke volume. The pulmonary capillary bed in mitral valve disease probably is at or near maximal distension anyway and is less able to respond to changes in total or pulsatile input into the system.

The volume of a passive vascular bed should increase with rise in intravascular pressure (44), and this is the known behavior of the normal pulmonary capillary bed $(3,4,6,7,45)$. In the group studied here, however, there was a negative correlation between $\mathrm{Vc}$ and intravascular pressure. This does not mean that in a given individual with mitral valve disease an acute rise in intravascular pressure would be associated with a further decrease in Vc, but in this group of patients, each studied under the same resting conditions, those patients with higher intravascular pressures had smaller pulmonary capillary volumes. The distensibility of the pulmonary capillary bed must be reduced in those cases of mitral valve disease with higher intravascular pressures. There may be passive constriction due to thickening of the capillary walls or structural obliteration of capillaries. On the other hand, some patients with normal or relatively mild elevation of pulmonary vascular pressures and resistance had a high normal Vc. This agrees with the finding of Palmer, Gee, Mills, and Bates (16) that $\mathrm{Vc}$ is increased in some moderately advanced cases of mitral stenosis but consistently reduced in the severest cases.

Not only is Vc inversely related to intravascular pressures, but the reduction in $\mathrm{Vc}$ is more closely related to the height of the pulmonary arterial pressure than to the left atrial pressure, which is also so with the ventilatory impairment found in mitral stenosis (46). McGaff, Roveti, Glassman, and Milnor (47) found that total pulmonary blood volume in rheumatic heart disease was positively related to left atrial pressure but was not related to pulmonary arterial pressure. The dif- ference in these pressure-volume relationships of the pulmonary vascular bed as a whole compared with the capillary bed suggests that the changes in total pulmonary blood volume with left atrial pressure rise are determined largely by changes in the venous compartment. These latter workers also found a negative correlation between pulmonary blood volume and pulmonary vascular resistance similar to the present relationship between $\mathrm{Vc}$ and resistance. In fact, the changes in $\mathrm{Vc}$ recorded here would in themselves be associated with a significant rise in total pulmonary vascular resistance.

The regression line in Figure 6 shows that for a mean rise in pulmonary vascular resistance from 5 to $15 \mathrm{RU} \cdot \mathrm{m}^{2}$ there is a drop in Vc from 49 to $21 \mathrm{ml}$ per $\mathrm{m}^{2}$. If this change in volume is due to reduction in number or length, or both, without change in radius of the individual capillaries, this would mean an increase in capillary resistance of $49 / 21$, or more than double. If there were a change in radius of individual capillaries without a change in number or length, the increase in capillary resistance would be $(49 / 21)^{2}$ or more than fivefold. Values for normal segmental resistance estimated by McGaff and associates (47) from the anatomical measurements of Miller (48) and Schleier (49) indicate that, in normal lungs, about $50 \%$ of the total pulmonary vascular resistance resides in the capillaries. No estimates are available for the contribution that the capillary bed makes to total pulmonary vascular resistance in disease states, but with a rise in total pulmonary vascular resistance in mitral valve disease from 5 to $15 \mathrm{RU} \cdot \mathrm{m}^{2}$, there would be an increase in capillary resistance of between two and five times, which is still a significant contribution. These figures can only be regarded as approximations but do suggest that reduction in the volume of the capillary bed, whether it be by reduction in length or cross-sectional area of capillaries, may contribute an important part of the total increase in pulmonary vascular resistance in mitral valve disease.

\section{Summary}

Measurements of pulmonary diffusing capacity for carbon monoxide, membrane diffusing capacity, and pulmonary capillary blood volume were made 
in 18 normal subjects and in 18 patients with mitral valve disease. Hemodynamic data were obtained under comparable conditions by left and right heart catheterization in the 18 patients with mitral valve disease and in nine of the normal subjects.

In the normal subjects, mean values $\pm \mathrm{SD}$ were for pulmonary diffusing capacity, $15.0 \pm 2.5$ ml CO per minute per $\mathrm{mm} \mathrm{Hg}$ per $\mathrm{m}^{2} \mathrm{BSA}$; for membrane diffusing capacity, $30 \pm 10.4 \mathrm{ml} \mathrm{CO}$ per minute per $\mathrm{mm} \mathrm{Hg}$ per $\mathrm{m}^{2} \mathrm{BSA}$; and for pulmonary capillary blood volume, $52 \pm 14.9 \mathrm{ml}$ per $\mathrm{m}^{2} \mathrm{BSA}$.

The mean value for pulmonary diffusing capacity in patients with mitral valve disease was significantly lower than normal, due mainly to impairment of membrane diffusing capacity. This impairment of membrane diffusion may be due in part to reduction in surface area available for diffusion by obliteration of part of the capillary bed, and, perhaps more important, to thickening of the alveolar-capillary membrane.

Increasing pulmonary vascular pressures and pulmonary vascular resistance are associated with diminution in the pulmonary capillary blood volume. Although these relationships could be explained by increasingly nonuniform distribution of capillary blood volume, it is equally likely that there is a true reduction in capillary blood volume as a result of either constriction or partial obliteration of the pulmonary capillary bed. This may be an important factor contributing to the elevation of pulmonary vascular resistance found in mitral valve disease.

\section{Acknowledgments}

I am greatly indebted to Dr. A. D. Jose for his helpful advice and support throughout the study. I thank Dr. John Read for his advice and suggestions in preparing the manuscript and Drs. Paul N. Yu and Frank W. Lovejoy, of Rochester, N. Y., for their original advice, and I gratefully acknowledge the technical assistance of Mrs. R. Godfrey-Smith and Miss T. Guilfoyle.

\section{References}

1. Forster, R. E., F. J. W. Roughton, L. Cander, W. A. Briscoe, and F. Kreuzer. Apparent pulmonary diffusing capacity for $\mathrm{CO}$ at varying alveolar $\mathrm{O}_{2}$ tensions. J. appl. Physiol. 1957, 11, 277.

2. Roughton, F. J. W., and R. E. Forster. Relative importance of diffusion and chemical reaction rates in determining the rate of exchange of gases in the human lung, with special reference to true diffusing capacity of pulmonary membrane and volume of blood in the lung capillaries. J. appl. Physiol. 1957, 11, 290.

3. Lewis, B. M., T-H Lin, F. E. Noe, and R. Komisaruk. The measurement of pulmonary capillary blood volume and pulmonary membrane diffusing capacity in normal subjects; the effects of exercise and position. J. clin. Invest. 1958, 37, 1061.

4. Lewis, B. M., W. T. McElroy, E. J. HayfordWelsing, and L. C. Samberg. The effects of body position, ganglionic blockade and norepinephrine on the pulmonary capillary bed. J. clin. Invest. 1960, 39, 1345.

5. Johnson, R. L., W. S. Spicer, J. M. Bishop, and R. E. Forster. Pulmonary capillary blood volume, flow and diffusing capacity during exercise. J. appl. Physiol. 1960, 15, 893.

6. Ross, J. C., G. E. Maddock, and G. D. Ley. Effect of pressure suit inflation on pulmonary capillary blood volume. J. appl. Physiol. 1961, 16, 674.

7. Ross, J. C., G. D. Ley, R. F. Coburn, J. L. Eller, and R. E. Forster. Influence of pressure suit inflation on pulmonary diffusing capacity in man. J. appl. Physiol. 1962, 17, 259.

8. McNeill, R. S., J. Rankin, and R. E. Forster. The diffusing capacity of the pulmonary membrane and the pulmonary capillary blood volume in cardiopulmonary disease. Clin. Sci. 1958, 17, 465.

9. Bates, D. V., C. T. Varvis, R. E. Donevan, and R. V. Christie. Variations in the pulmonary capillary blood volume and membrane diffusion component in health and disease. $\mathrm{J}$. clin. Invest. 1960, 39, 1401.

10. Flatley, F. J., H. Constantine, R. M. McCredie, and P. N. Yu. Pulmonary diffusing capacity and pulmonary capillary blood volume in normal subjects and in cardiac patients. Amer. Heart J. 1962, 64, 159.

11. Bucci, G., and C. D. Cook. Studies of respiratory physiology in children. VI. Lung diffusing capacity, diffusing capacity of the pulmonary membrane and pulmonary capillary blood volume in congenital heart disease. J. clin. Invest. 1961, 40, 1431.

12. Stein, M., P. Kimbel, and R. L. Johnson, Jr. Pulmonary function in hyperthyroidism. J. clin. Invest. $1961,40,348$.

13. Burgess, J. H., and J. M. Bishop. Pulmonary diffusing capacity and its subdivisions in polycythemia vera. J. clin. Invest. 1963, 42, 997.

14. Rankin, J., and Q. C. Callies. Diffusion characteristics of the human lung in congenital and acquired heart disease (abstract). Circulation 1958, 18, 768.

15. Rankin, J., and Q. C. Callies. The influence of atrial and ventricular septal defect on the capil- 
lary bed of the lung and on the diffusing characteristics of the pulmonary membrane. J. Lab. clin. Med. 1958, 52, 937.

16. Palmer, W. H., J. B. L. Gee, F. C. Mills, and D. V. Bates. Disturbances of pulmonary function in mitral valve disease. Canad. med. Ass. J. 1963, 89, 744.

17. Daly, W. J., S. T. Giammona, J. C. Ross, and H. Feigenbaum. Effects of pulmonary vascular congestion on postural changes in the perfusion and filling of the pulmonary vascular bed. J. clin. Invest. 1964, 43, 68.

18. Ogilvie, C. M., R. E. Forster, W. S. Blakemore, and J. W. Morton. A standardized breath holding technique for the clinical measurement of the diffusing capacity of the lung for carbon monoxide. J. clin. Invest. 1957, 36, 1.

19. Cournand, A., J. S. Baldwin, and A. Himmelstein. Cardiac Catheterization in Congenital Heart Disease. New York, Commonwealth Fund, 1949.

20. Ross, J., Jr., E. Braunwald, and A. G. Morrow. Left heart catheterization by the transseptal route. A description of the technic and its applications. Circulation 1960, 22, 927.

21. Hamilton, W. F., J. W. Moore, J. M. Kinsman, and R. G. Spurling. Studies on the circulation. IV. Further analysis of the injection method, and of changes in hemodynamics under physiological and pathological conditions. Amer. J. Physiol. 1932, 99, 534.

22. Roos, A., and J. A. Rich. Spectrophotometric determination of oxyhemoglobin saturation and oxygen content of blood. J. Lab. clin. Med. 1952, 40, 431.

23. Bates, D. V., N. G. Boucot, and A. E. Dormer. The pulmonary diffusing capacity in normal subjects. J. Physiol. (Lond.) 1955, 129, 237.

24. Rahn, H., and A. B. Otis. Continuous analysis of alveolar gas composition during work, hyperpnea, hypercapnia and anoxia. J. appl. Physiol. 1949, $1,717$.

25. Forster, R. E., F. J. W. Roughton, F. Kreuzer, and W. A. Briscoe. Photocolorimetric determination of rate of uptake of $\mathrm{CO}$ and $\mathrm{O}_{2}$ by reduced human red cell suspensions at $37^{\circ} \mathrm{C}$. J. appl. Physiol. 1957, 11, 260.

26. Roughton, F. J. W., R. E. Forster, and L. Cander. Rate at which carbon monoxide replaces oxygen from combination with human hemoglobin in solution and in the red cell. J. appl. Physiol. 1957, 11, 269.

27. Cournand, A., E. deF. Baldwin, R. C. Darling, and D. W. Richards, Jr. Studies on intrapulmonary mixture of gases. IV. The significance of the pulmonary emptying rate and a simplified open circuit measurement of residual air. J. clin. Invest. 1941, 20, 681 .

28. Mainland, D. Some undesirable effects of laboratory tradition in Methods in Medical Research, J. M.
Steele, Ed. Chicago, Year Book Publishers, 1954, vol. 6 , p. 178 .

29. Burrows, B., A. H. Niden, C. Mittman, R. C. Talley, and W. R. Barclay. Non-uniform pulmonary diffusion as demonstrated by the carbon monoxide equilibration technique: experimental results in man. J. clin. Invest. 1960, 39, 943.

30. Lewis, B. M., E. J. Hayford-Welsing, A. Furusho, and L. C. Reed, Jr. Effect of uneven ventilation on pulmonary diffusing capacity. J. appl. Physiol. $1961,16,679$.

31. Doyle, A. E., J. F. Goodwin, C. V. Harrison, and R. E. Steiner. Pulmonary vascular patterns in pulmonary hypertension. Brit. Heart J. 1957, 19, 353.

32. Dollery, C. T., and J. B. West. Regional uptake of radioactive oxygen, carbon monoxide and carbon dioxide in the lungs of patients with mitral stenosis. Circulat. Res. 1960, 8, 765.

33. Ball, W. C., Jr., P. B. Stewart, L. G. S. Newsham, and D. V. Bates. Regional pulmonary function studied with xenon ${ }^{133}$. J. clin. Invest. 1962, 41, 519.

34. West, J. B., and C. T. Dollery. Distribution of blood flow and ventilation-perfusion ratio in the lung, measured with radioactive $\mathrm{CO}_{2}$. J. appl. Physiol. 1960, 15, 405.

35. Read, J., D. J. C. Read, and M. C. F. Pain. Influence of nonuniformity of the lungs on steadystate measurements of pulmonary diffusion capacity for carbon monoxide. Submitted for publication.

36. MacIntosh, D. J., J. C. Sinnott, I. G. Milne, and E. A. S. Reid. Some aspects of disordered pulmonary function in mitral stenosis. Ann. intern. Med. 1958, 49, 1294.

37. Riley, R. L., C. J. Johns, G. Cohen, J. E. Cohn, D. G. Carroll, and R. H. Shepard. The diffusing capacity of the lungs in patients with mitral stenosis studied post-operatively. J. clin. Invest. 1956, 35,1008 .

38. Auchincloss, J. H., Jr., R. Gilbert, and R. H. Eich. The pulmonary diffusing capacity in congenital and rheumatic heart disease. Circulation 1959, 19, 232.

39. Cosby, R. S., E. C. Stowell, Jr., W. R. Hartwig, and M. Mayo. Pulmonary function in left ventricular failure, including cardiac asthma. Circulation 1957, 15, 492.

40. Donevan, R. E., W. H. Palmer, C. J. Varvis, and D. V. Bates. Influence of age on pulmonary diffusing capacity. J. appl. Physiol. 1959, 14, 483.

41. Parker, F., Jr., and S. Weiss. The nature and sig. nificance of the structural changes in the lungs in mitral stenosis. Amer. J. Path. 1936, 12, 573.

42. McCredie, R. M., F. W. Lovejoy, and P. N. Yu. Pulmonary diffusing capacity and pulmonary capillary blood volume in patients with intracardiac shunts. J. Lab. clin. Med. 1964, 63, 914. 
43. Milnor, W. R., A. D. Jose, and C. J. McGaff. Pulmonary vascular volume, resistance, and compliance in man. Circulation 1960, 22, 130.

44. Burton, A. C. The relation between pressure and flow in the pulmonary bed in Pulmonary Circulation. W. R. Adams and E. V. Keith, Eds. 1958.

45. Rosenberg, E., and R. E. Forster. Changes in diffusing capacity of isolated cats lungs with blood pressure and flow. J. appl. Physiol. 1960, 15, 883.

46. Krautwald, A., J. Garten, H. Hähnel, J. Kiessling, D. Kolmar, and A. Lichterfeld. Ventilations- funktion und Hämodynamik bei Mitralstenosen. Z. Kreisl.-Forsch. 1961, 50, 340.

47. McGaff, C. J., G. C. Roveti, E. Glassman, and W. R. Milnor. The pulmonary blood volume in rheumatic heart disease and its alteration by isoproterenol. Circulation 1963, 27, 77.

48. Miller, W. S. The structure of the lung. J. Morph. 1893, 8, 165.

49. Schleier, J. Der Energieverbrauch in der Blutbarn. Pflügers Arch. ges. Physiol. 1919, 173, 172. 